\title{
Best interests
}

\section{Editor}

Joe Bouch

\begin{tabular}{|c|c|c|}
\hline Editorial Board & Sheila Hollins & Editorial Assistan \\
\hline Gwen Adshead & Cornelius Katona & Jonica Thomas \\
\hline J.S. Bamrah & Helen Killaspy & Sophie Worth \\
\hline Dinesh Bhugra & David Owens & \\
\hline Nick Brown & Femi Oyebode & Staff Editors \\
\hline Alistair Burns & Jan Scott & Kasia Krawczyk \\
\hline Patricia Casey & Tom Sensky & Lynnette Maddock \\
\hline David Castle & Steven Sharfstein & Zosia O'Connor \\
\hline John Cookson & Michael Smith & \\
\hline Colin Drummond & Peter Tyrer & \\
\hline Jonathan Green & David Yeomans & \\
\hline
\end{tabular}

\section{Subscriptions}

Advances Volume 16, 2010 (six issues)

(full airmail £19/US\$34 extra)

Members of the
Royal College
of Psychiatrists Non-members Institutions

\begin{tabular}{lccc}
\hline Print (+free online) & & & \\
Europe (\& UK) & $£ 62$ & $£ 130$ & $£ 141$ \\
USA & US\$110 & US $\$ 205$ & US\$243 \\
Elsewhere & $£ 69$ & $£ 140$ & $£ 152$
\end{tabular}

Online (only)

Worldwide

£39/US\$63 £103/US\$155 £128/US\$199

Payment may be made by cheque/money order, by Access/Master Card/ Visa/American Express, or by UNESCO coupons. EC subscribers: please supply your Member State Code and Value Added Tax (VAT) number.

Payment should be made to Maney Publishing, Suite 1C, Joseph's Well, Hanover Walk, Leeds LS3 1AB, UK (tel: +44 (0)113 243 2800; fax: +44 (0)113 386 8178; email: subscriptions@maney.co.uk). For subscriptions in North America, please contact Maney Publishing North America, 875 Massachusetts Avenue, 7th Floor, Cambridge, MA 02139, USA (tel: 866 2975154 (toll-free); fax: 617354 6875; email: maney@maneyusa.com).

Continuing professional development (CPD) Those wishing to register for CPD with the Royal College of Psychiatrists should contact the CPD unit (tel: +44 (0)20 72352351 , ext. 6108 or 6112$)$. There is no charge for participation in the CPD scheme for Members, Fellows and Affiliates of the College.

CPD Online The College also publishes an interactive online learning facility for CPD in psychiatry. Further details, sample modules and subscription information can be viewed at www.psychiatrycpd.co.uk. Discounts are available for Advances subscribers.

Correspondence Letters submitted for publication should be emailed to Dr Joe Bouch at apt@rcpsych.ac.uk or posted to Advances in Psychiatric Treatment, Royal College of Psychiatrists, 17 Belgrave Square, London SW1X 8PG.

Printed by Henry Ling Ltd, 23 High East Street, Dorchester, Dorset DT1 $1 \mathrm{HD}$.

(C) The Royal College of Psychiatrists 2010. Published by the Royal College of Psychiatrists, a charity registered in England and Wales (228636) and in Scotland (SC038369). Unless so stated, material in Advances in Psychiatric Treatment does not necessarily reflect the views of the Editor or the Royal College of Psychiatrists. The publishers are not responsible for any errors of omission or fact.

The College crest is a registered trade mark of the Royal College of Psychiatrists.

ISSN 1355-5146

\section{By Joe Bouch}

Determining the patient's best interests is an underpinning principle of capacity legislation (Brindle \& Branton, pp. 430-437, Box 2) and surely of all clinical practice. It is perhaps nowhere more controversial than in the use of medication to treat young people with mental health problems described as a 'blunt' approach and 'bad medicine' by Des Spence (2010), a practising GP and regular columnist in the BMJ. A more measured JAMA editorial (Varley 2009) discusses some of the concerns: the substantial increase in the use of antipsychotics in young people (including children younger than 5 diagnosed with bipolar disorder); diagnostic problems, including the overlap of bipolar disorder with behaviour disorders and the possible discontinuity between child and adolescent and adult forms of bipolar disorder; the relative prioritising of medications and psychosocial interventions; the long-term health implications of prolonged treatment with second-generation antipsychotics (not least obesity); and the extent to which the evidence base is formed by industry-sponsored investigations. It is clear, then, that determining appropriate treatment and the best interests of a young person with an affective disorder is unlikely to be straightforward.

Dubicka et al (pp. 402-412) consider prescribing by examining and reflecting critically on the evidence without shying away from the controversial issues. Accurate diagnosis, necessary for both good prescribing (British Pharmacological Society 2010) and steering clear of causing avoidable harm, is problematic. So, too, is the evidence base, which is sparse and at times depends on extrapolating from the adult literature. Even randomised controlled trials, often referred to as the gold standard (e.g. Coia, pp. 474-475), are not necessarily so and are 'particularly weak in relationship to generalisability and most especially in the assessment of harms' (Rawlins 2008). Importantly, Dubicka et al do not consider pharmacological treatment as a standalone intervention but always in addition to 'specialised treatment as usual' (STAU). Distinct from specialised psychological treatments such as cognitive-behavioural therapy and interpersonal therapy, STAU comprises no fewer than 16 elements (Box 1, p. 404) and describes the complex and multifaceted quality of 'ordinary' multidisciplinary and multi-agency clinical practice.

\section{Capacity and best interests decisions}

Such 'ordinary' practice is outlined in the article by Biswas \& Hiremath (pp. 440-447), which is my Editor's pick for this issue. Based on a real clinical case, it brings to life how to support a patient making an important decision for themselves, when to apply capacity legislation and how to implement it. It exemplifies thoughtful clinical practice and teamwork. Although describing a mature adult with intellectual disability facing surgery for breast cancer, the principles could equally apply to initiating medical treatment in a young person diagnosed with an affective disorder.

British Pharmacological Society (2010) Ten Principles of Good Prescribing. BPS (http://www.bps.ac.uk/uploadedfiles/ PMeBulletinUploads/BPSPrescribingStatement03Feb2010.pdf).

Rawlins M (2008) De Testimonio: on the evidence for decisions about the use of therapeutic interventions. Clinical Medicine 8: 579-88.

Spence D (2010) Bad medicine: medicated minors. BMJ 341: c3907.

Varley KV, McClellan J (2009) Implications of marked weight gain associated with atypical antipsychotic medications in children and adolescents. JAMA 302: 1811-2. 